\title{
Johann $\mathbb{C}$ hriftoph 2 Rojt
}

Ein Beitrag

jur Bejhhichte der deutjchen Eitteratur

im 18. Jaḩrh̨undert.

von

\section{Bứtav $\mathfrak{W} \mathfrak{a h l}$}

Dr. phil.

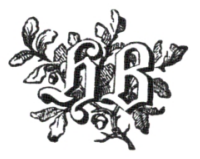

Eeipzig

J. C. Ginridhs'ihe Buhhandlung

1902 



\section{Meinem Dater}

in đreue und Danf́barfeit,

\section{Dem Zlndenfen meiner Mlutter}

in weḩmütiger Erinnerung

gewiomet. 
